Journal of Research in

Nanoscience and Nanotechnology

Journal homepage:

http://akademiabaru.com/submit/index.php/jrnn/index

ISSN: $2773-6180$

\title{
Biosynthesis and Characterization of Silver Nanoparticles from Bitter Melon (Momordica charantia) Fruit and Seed Extract and their Antimicrobial Activity
}

\author{
Umme Ruman ${ }^{1 *}$, Poonah Kia² \\ Putra Malaysia, UPM Serdang 43400, Selangor, Malaysia ${ }^{1}$ \\ Serdang 43400, Selangor, Malaysia ${ }^{2}$ \\ * Correspondence email: chaity101@gmail.com \\ https://doi.org/10.37934/jrnn.2.1.111
}

Materials Synthesis and Characterization Laboratory, Institute of Advanced Technology (ITMA), Universiti

Laboratory of Vaccine and Immunotherapeutic, Institute of Bioscience Universiti Putra Malaysia, UPM

\section{ABSTRACT}

Momordica charantia is a phenolic rich vegetable. In this study, the fruits and seeds extract of $M$. charantia were used to synthesize silver nanoparticles (Ag NPs) using biotechnological approach. Structural, morphological, and antimicrobial properties of the synthesized Ag-NPs were characterized using UV/Vis Spectrophotometry, Dynamic Light Scattering (DLS), High Resolution Transmission Electronics Microscopy (HRTEM), Field Emission Scanning Electron Microscopy (FESEM), Fourier Transform Infrared Spectroscopy (FTIR) and X-Ray diffraction (XRD). In DLS, the average particle size of Ag-NPs was found $17.5 \pm 2.1 \mathrm{~nm}$ and $18.3 \pm 1.9 \mathrm{~nm}$ using seed and fruit extract, respectively. HRTEM has revealed their spherical structure for both seed and fruit extract of M. charantia. FESEM images found Ag-NPs with the size between $\sim 20$ and $~ 35$ $\mathrm{nm}$. The Ag NPs exhibited Surface Plasmon Resonance (SPR) centered at $405 \mathrm{~nm}$ for seed extract and $402 \mathrm{~nm}$ for fruit extract using a UV-visible spectrophotometer. FT-IR results showed phenolic and carbohydrate compounds involved in the synthesis of the Ag NPs. Furthermore, the synthesized Ag NPs has found highly rich in antibacterial properties against Escherichia coli and Pseudomonas aeruginosa bacterium. Thus, bioconversion of Ag NPs by M. charantia could be employed as a potential antibacterial source to eliminate pathogenic microorganisms from agricultural and food preservation industry.

Keywords:

Green synthesis, Silver nanoparticles,

Antimicrobial, Momordica charantia,

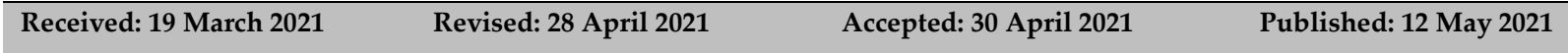




\section{Introduction}

Nanotechnology is one of the upcoming fields of research in modern science. The word "Nano" is derived from the Greek word "dwarf "which means one billionth. A nanometer is one billionth of a meter (10-9) and it might be represented by the length of ten hydrogen atoms lined up in a row [1, 2]. In nanotechnology, various nanoparticles have been showing potential in many areas such as agricultural, medical, electronics, and environmental fields. Nanoparticle is the most unique discovery in nanotechnology. Nanoparticles with new or improved properties, such as size, distribution and morphology and their excellent physicochemical and biological properties have exhibited more effective in various application compared to bulk chemical composition, due to their high surface-to-volume ratio, penetration capability, and low side effects [3, 4].

Among other nanoparticles metallic nanoparticles have different physical and chemical properties from bulk metals such as size, orientation, lower melting points, higher specific surface areas, specific optical properties, mechanical strengths, and specific magnetizations. All these properties are useful in various industrial applications and these properties can potentially change the performance of any material [5,6]. For many applications of nanoparticles, the scientific community has extensively effort to develop suitable synthetic techniques for producing nanoparticles. However, various physiochemical approaches are limited by the environmental pollution caused by chemical compounds during the synthesis of metal nanoparticles. Due to the advantages of nontoxicity, reproducibility in production, easy scaling-up, and well-defined morphology, biological method such as biosynthesis or green synthesizing nanoparticle has become a new trend in nanoparticle production $[7,8]$. The biosynthesis over chemical and physical synthesis are environment friendly, cost effective and easily scaled up for large scale synthesis, besides there is no need to use high temperature, pressure, energy, and toxic chemicals $[9,10]$. For all these reasons, green synthesis of nanoparticles from plant extract comes over the chemical and physical synthesis methods.

Among several noble metal nanoparticles, Ag-NPs have potentially utilized in many applications. Silver is a well-known antimicrobial agent against a wide range of over 650 microorganisms from different classes such as gram-negative and gram-positive bacteria, fungi, and viruses. In 1884, during childbirth it became a common practice to administer drops of aqueous silver nitrate to new-born baby's eyes to prevent the transmission of Neisseria gonorrhea from infected mothers. Silver has the most effective antibacterial action and is least toxic to animal cells comparatively than other metals. Silver is generally used in the nitrate form to induce antimicrobial action. However, due to high amount requirement, the substitute of silver nitrate to Ag-NPs are more beneficial to the application. Nanoparticles have a huge increase in the surface area for the microbes to be exposed to which makes silver nanoparticle more effective antimicrobial agent compare to chemical form of silver nitrate [11, 12].

Momordica charantia is a vegetable from Momordica cymbalaria climber plants belonging to the family of Cucurbitaceae. It is commonly known as bitter gourd or bitter melon in English. It is initially has found in Southern India and South East Asian countries and currently found all over the world. The vegetable includes the fruit and seed containing high levels of antioxidant properties, phenolic compounds, calcium, potassium, vitamin $C$ and fiber content $[13,14]$.

For metal nanoparticles synthesis, many scientists have been used plant extract from different sources. In this study, the fruit and seed aqueous extracts of bitter melon ( $M$. charantia) were used as reducing and capping agents to synthesize Ag-NPs through a completely biological process. 
Additionally, the antimicrobial potential of biosynthesized nanoparticles was assessed against some pathogenic microorganisms of E. coli, P. aeruginosa. M. charantia has found four main constituents of the phenolic acids-catechin, gallic acid, gentisic acid, chlorogenic acid. The most phenolic acids contained in bitter melon were catechin and gallic acid [15-17]. The phenolic acid works as both reducing and capping agents which converts silver ions $\left(\mathrm{Ag}^{+}\right)$to Ag-NPs and covers the surfaces of formed nanoparticles and prevents from the agglomerations [18]. Silver in nanoparticle form is more efficient than silver ions in terms of its antimicrobial activity. It is also known to exert lower toxicity to mammalian cells as well [19].

\section{Materials and Methods}

\subsection{Materials}

Materials: $\mathrm{AgNO}_{3}$ (99.98\%) as silver precursor was supplied from Merck (Darmstadt, Germany), Bitter melon was purchased from a local market. All the solutions were prepared with deionized water.

\subsection{Preparation of Bitter Melon (M.charantia) Extract}

$M$. charantia fruit and seed were used to make the aqueous extract to synthesize silver nanoparticles. Bitter melon (M. charantia) was carefully washed with distilled water, cut into fine pieces, dried in oven drier at 1200 C, $24 \mathrm{~h}$. After drying the seed and fruit parts were separated and crushed into powders separately. The powders of $M$. charantia were boiled in distilled water about 30-45 min and filtered through Whatman No.1 filter paper (pore size $125 \mathrm{~mm}$ ) and then, the extracts were collected and stored at $4{ }^{\circ} \mathrm{C}$ before use.

\subsection{Synthesis of Silver Nanoparticles}

The Erlenmeyer flask containing $50 \mathrm{~mL}$ of $M$. charantia extracts of seed and fruit were mixed separately with $0.05 \mathrm{~m} / \mathrm{moL}$ of $\mathrm{AgNO}_{3}$ under continuous stirring at $30^{\circ} \mathrm{C}$. The color of solutions was changed from light brown into dark brown color after several min which indicates formation of silver nanoparticle (Figure 1). The dark brown solid products were collected through centrifugation at 4000 rpm for 15 min. After washing several times with distilled water, the obtained solid products were dried in an oven at $60^{\circ} \mathrm{C}$. The final powders were stored in airtight bottles for further analysis.

\subsection{Physicochemical Characterization}

The UV spectrophotometry name PerkinElmer precisely Lambda $25 \mathrm{UV} /$ Vis spectrophotometer was used in order to analyses UV at room temperature operated at a resolution of $1 \mathrm{~nm}$ between 200 and $1000 \mathrm{~nm}$ ranges. The characterizations of Ag NPS were done using the dynamic light scattering (Nanosizer, Malvern, NanoS, Malvern Panalytical Ltd., United Kingdom) for particle size distribution and polydispersity index (PDI). The X-ray diffraction (Shimadzu XRD 6000, Kyoto, Japan) was used for crystalline phase analysis at $2-60^{\circ}$ range using $\mathrm{CuK} \alpha$ radiation $(\lambda=1.54060 \AA)$ at $40 \mathrm{kV}$ and $30 \mathrm{~mA}$. High Performance Transmission electron microscope (Hitachi H-7100, Tokyo, Japan) was used for morphological characteristics, at $100 \mathrm{kV}$ accelerating voltage using carbon film, 300 mesh copper grids. The Field emission scanning electron microscope (FESEM, Nova ${ }^{\mathrm{TM}}$ NanoSEM 230 - FEI Company, California, and USA) was used for surface morphology and shape analysis. The Fourier transform infrared spectroscopy (FTIR) for functional group analysis was done using FT-IR spectrometer (Perkin Elmer, SPECTRUM 1000, NJ, USA) with a resolution of $4 \mathrm{~cm}^{-1}$. 


\subsection{Antibacterial Activity Test}

The antibacterial activities of Ag-NPs were carried out by disc diffusion method. Muller Hinton Ager plates were prepared, sterilized, and solidified. After solidification E. coli and Pseudomonas aeruginosa bacterial cultures were swabbed on these plates. The sterile blank discs were dipped in Ag-NPs solution $(10 \mathrm{mg} / \mathrm{ml})$ and placed in the Muller Hinton Agar and kept for incubation at $37^{\circ} \mathrm{C}$ for 24 hours.

\section{Results and Discussion}

\subsection{Synthesis of $A g-N P S$}

Since reducing agents for silver nanoparticle synthesis are often considered toxic or hazardous, the use of green synthesis methods is becoming a priority [13]. Bitter melon has the polyphenolic compounds which are useful to synthesize nanoparticles. Polyphenols are typically act as reducing and capping agents to synthesize silver nanoparticle [20]. It is well known that Ag-NPs exhibit yellowish brown color in aqueous solution due to excitation of Surface Plasmon Resonance (SPR) in Ag-NPs [21]. The reduction of silver ion (Ag+) to Ag-NPs by using of M. charantia extracts containing of many polyphenols and flavones as both reducing and stabilizing agent could be followed by the color change from yellow to dark brown during the incubation period of $35-45 \mathrm{~min}$ at $30^{\circ} \mathrm{C}$ (Figure 1).
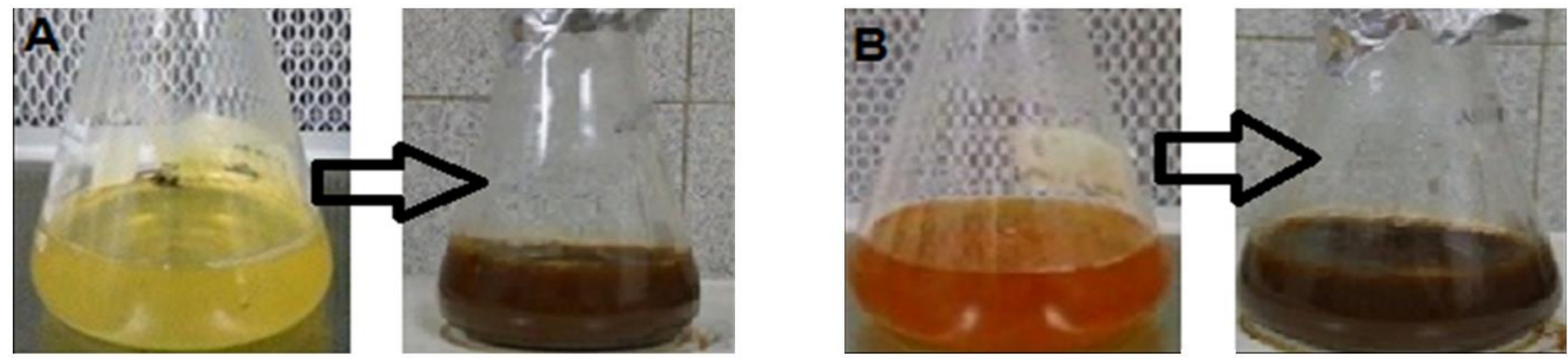

Figure 1: Colour change of (A) seed extract and (B) fruit extract before and after synthesis of Ag-

NPs

\section{$3.2 \mathrm{pH}$ analysis}

The initial $\mathrm{pH}$ of solution was changed in the end of reaction. Table 1 has shown the $\mathrm{pH}$ of seeds and fruits extract NPs in solution. As the $\mathrm{pH}$ value did not found considerable difference, so it can be not a factor in synthesis parameter.

Table 1. pH conditions for synthesis of Ag- NPs.

\begin{tabular}{rcccc}
\hline Extract & $\begin{array}{c}\text { Temperature } \\
\left({ }^{\circ} \mathbf{C}\right)\end{array}$ & $\begin{array}{c}\text { Initial } \\
\mathbf{P H}\end{array}$ & $\begin{array}{c}\text { Final } \\
\mathbf{P H}\end{array}$ & $\begin{array}{c}\text { Approximate } \\
\text { time }\end{array}$ \\
\hline Seed & 30 & 7.52 & 6.51 & $35 \mathrm{~min}$ \\
Fruit & 30 & 7.29 & 6.30 & $45 \mathrm{~min}$ \\
\hline
\end{tabular}

\subsection{Dynamic Light Scattering analysis}

Particle size found by the DLS machine with PDI $>0.7$ index considering the broad particle size distribution of seed extract and fruit extract synthesis of Ag-NPs are shown in Figure 2. Figure 2A shown the seed extract Ag-NPs with size of $18.3 \pm 1.9 \mathrm{~nm}$ and fruit extract synthesis of Ag-NPs are 
shown in figure $2 \mathrm{~B}$ with size of $17.5 \pm 2.1 \mathrm{~nm}$. Both fruit and seed extract-based Ag-NPs has shown similar nanometre size in DLS confirming the nano diameter of particles formation. Due to hydrodynamic size, the DLS size is showing slightly bigger than then HRTEM size.
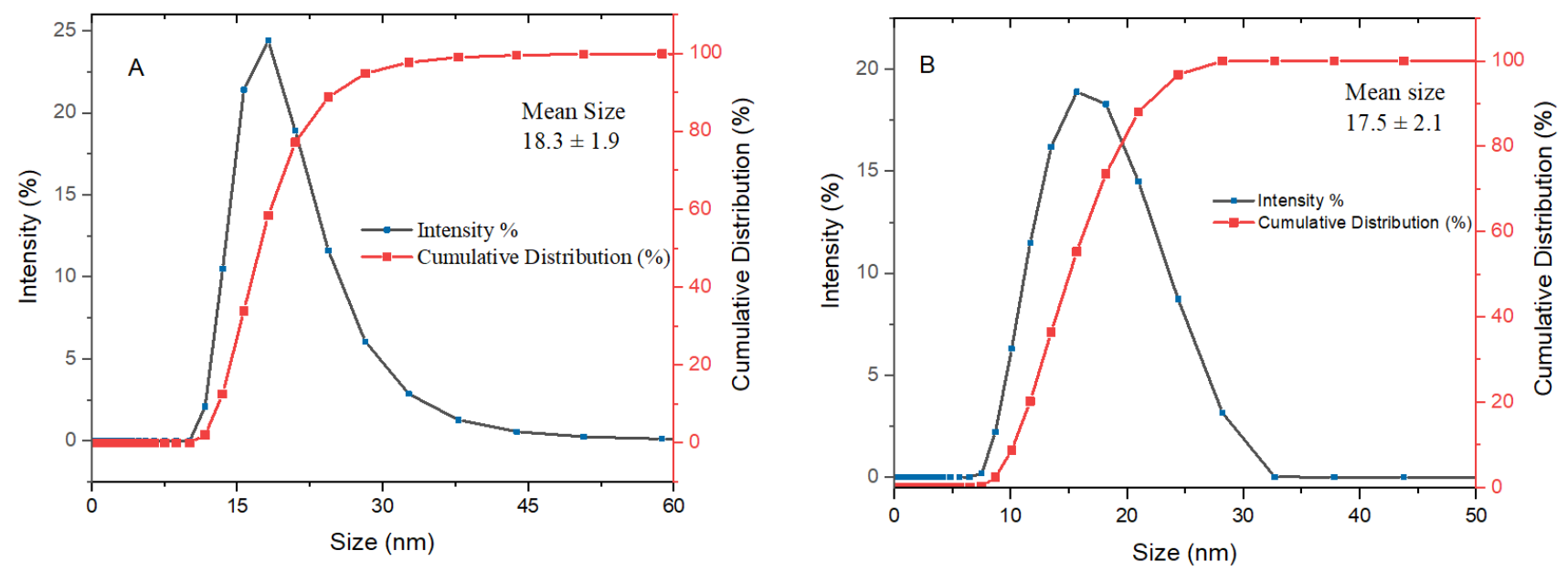

Figure 2. Particles size distribution by the intensity and cumulation of (A) seed extract and (B) fruit extract synthesis of Ag-NPs

\subsection{UV/Vis Spectrophotometry analysis}

UV-Vis spectroscopy could be used to examine size and shape-controlled nanoparticles in aqueous suspensions [22]. The peaks were found at 401 and $402 \mathrm{~nm}$ for silver nanoparticle synthesized by fruit and seed extracts respectively in Figure 3A and 3B confirming the formation of Ag-NPs. The spectra result from the excitation of SPR due to the reduction of silver ions to Ag-NPs in the extract [23]. The spherical Ag-NPs display the characteristic SPR at the wavelength between the ranges of $400-450 \mathrm{~nm}$ [24].
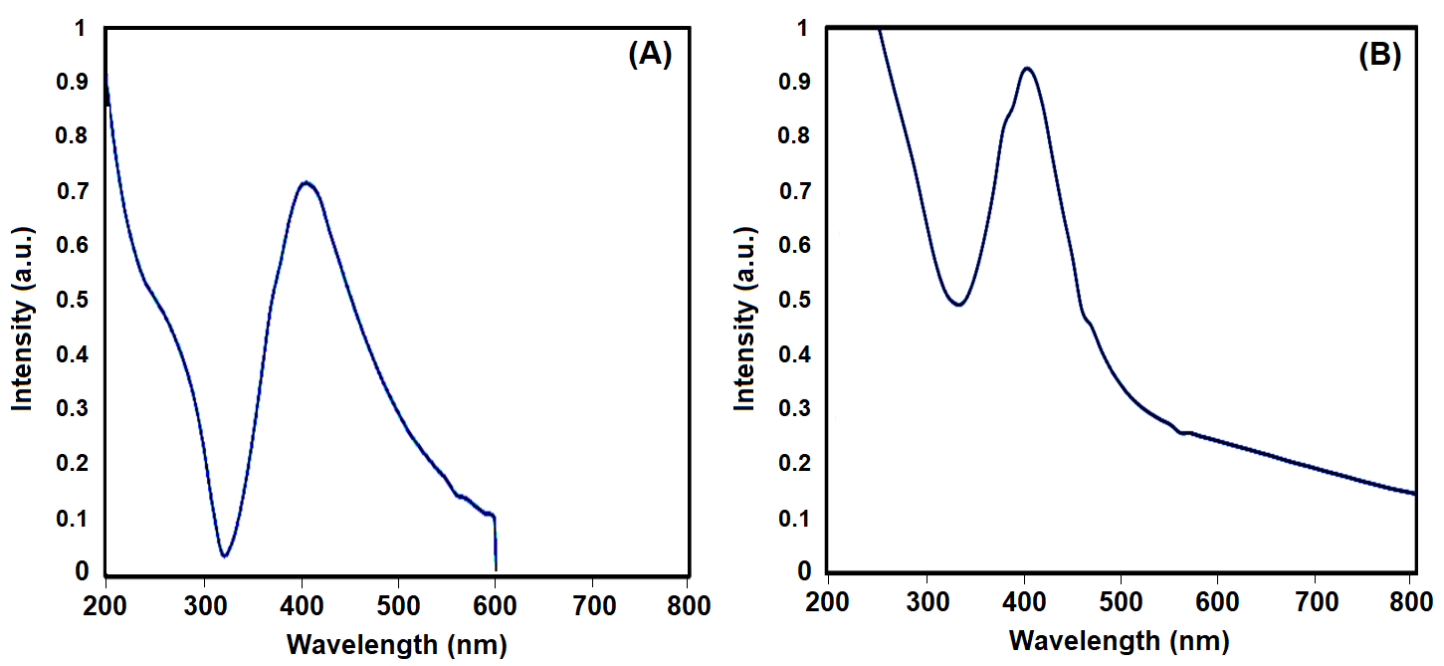

Figure 3. FTIR spectra of Ag-NPs synthesized by (A) Fruit and (B) seed extract.

\subsection{X-Ray Diffraction analysis}

The X-ray diffraction patterns of seed extract and fruit extract synthesis of Ag-NPs are shown in Figure 4. The XRD patterns of Ag-NPs shows that the biosynthesized particles are crystalline with 
small sizes. The lattice planes (111), (200), (220), and (311) were established with the corresponding Bragg's angles of $38.45^{\circ}, 45.21^{\circ}, 64.87^{\circ}$, and $76.36^{\circ}$, respectively, which confirm the face-centered cubic structure of the bio-formed Ag-NPs. The sizes of formed Ag-NPs were calculated by using Scherer's equation [25] by determining the width of the (111) Bragg reflection and were estimated to be around 14 and $9 \mathrm{~nm}$ for Ag-NPs synthesized via fruit and seed extract, respectively.

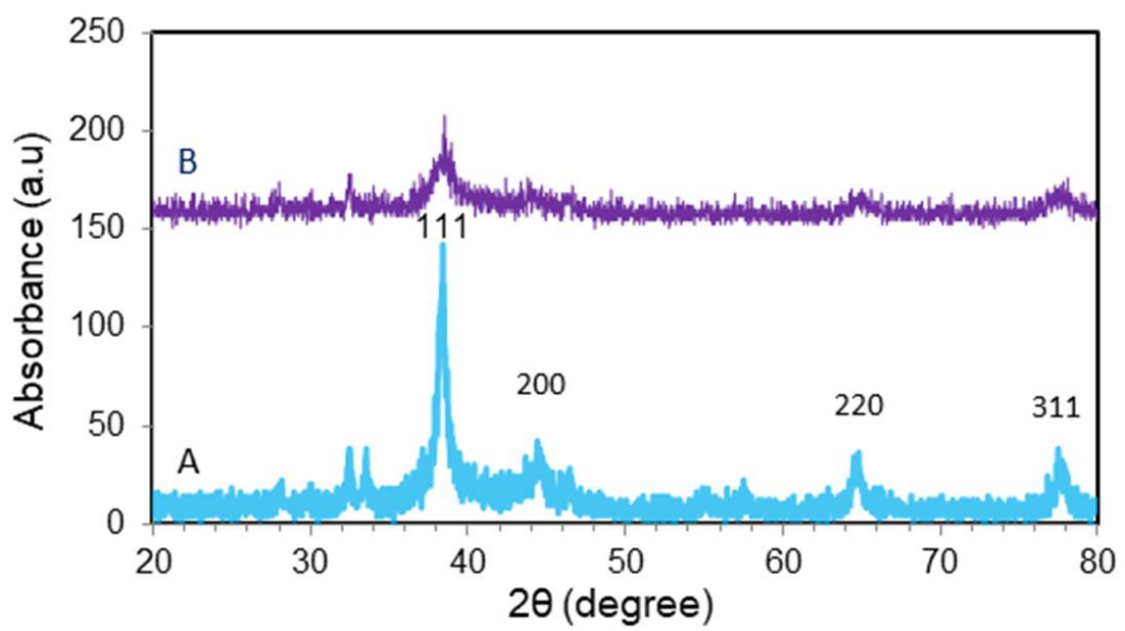

Figure 4. XRD diffraction pattern of Ag-NPs synthesized by (A) Fruit and (B) seed extract.

\subsection{High Resolution Transmission Electronics Microscopy (HRTEM)}

The morphology and size of Ag-NPs were determined by TEM images. Based on HRTEM micrographs (Figure 5A and 5B), it was observed that Ag-NPs were mostly spherical in shape with uniform structure. The average particle sizes of Ag-NPs were $7.5 \pm 2.1 \mathrm{~nm}$ and $10.3 \pm 1.9 \mathrm{~nm}$ synthesized using seed and fruit extracts, respectively. The observation of HRTEM image analysis has confirmed the nanoparticles synthesis.
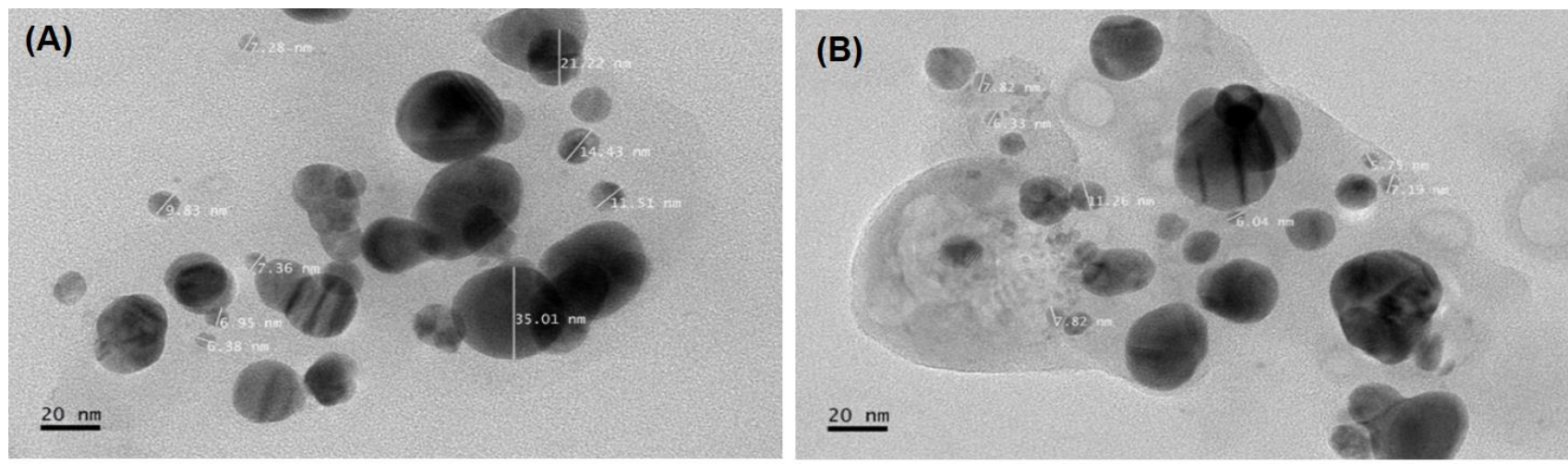

Figure 5. TEM images of (A) fruit and (B) seed extracts synthesized Ag-NPs.

\subsection{Field Emission Scanning Electron Microscopy}

FESEM observations further confirm the formation of the Ag-NPs using of Momordica charantia extracts. The morphology of green synthesized Ag-NPs was viewed by FESEM as were shown in Figure 6A and 6B. FESEM images show agglomerated Ag-NPs with the averages size between $~ 10$ and $\sim 30 \mathrm{~nm}$ was synthesized by seed and fruit extract, respectively. The particles are clearly identified by their spherical shapes. The FESEM results are well match with the HRTEM observations. The surface morphology was observed by FESEM images of both Ag-NPs. The results were conducted 
with the powder form of the nanoparticles, as a result, the agglomeration was observed in the Figure 6.
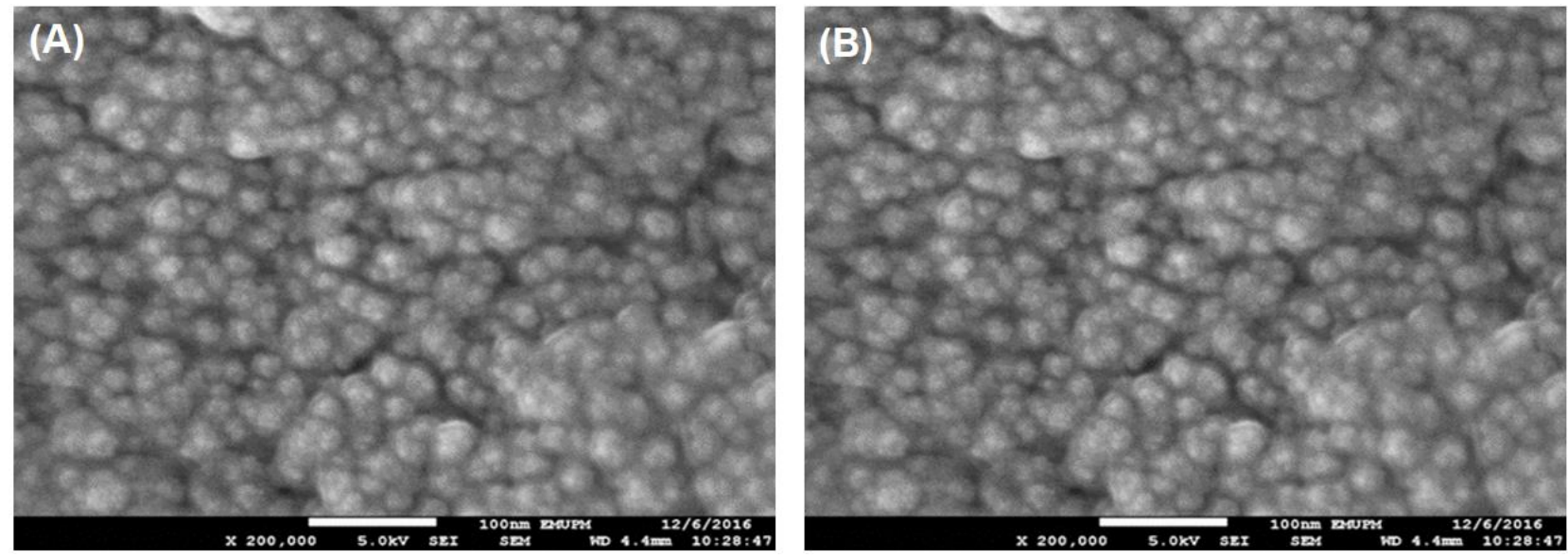

Figure 6. FESEM images of (A) fruit and (B) seed extracts synthesized Ag-NPs.

\subsection{Fourier Transform Infrared Spectroscopy (FTIR)}

FTIR measurements were carried out to identify the biomolecules involved in the reduction process $\mathrm{Ag}^{\circ} \rightarrow \mathrm{Ag}$-NPs and the efficient stabilization of the synthesized silver nanoparticles. In Figure 6, it was found that in silver nanoparticle fruit extract, the band found in $1697.36 \mathrm{~cm}^{-1}$ and $1604.77 \mathrm{~cm}$ ${ }^{1}$ which corresponds to carbonyl $(\mathrm{C}=\mathrm{O})$ Stretch and Amide NHC $=\mathrm{O}$ Stretch and in Ag-NPs seed extract, the bond found in $1705.07 \mathrm{~cm}^{-1}$ which represents $\mathrm{C}=\mathrm{O}$ Stretch. Carbonyl groups confirm the phenolic compound in the extract. The carbonyl stretching absorption is one of the strongest IR absorptions.

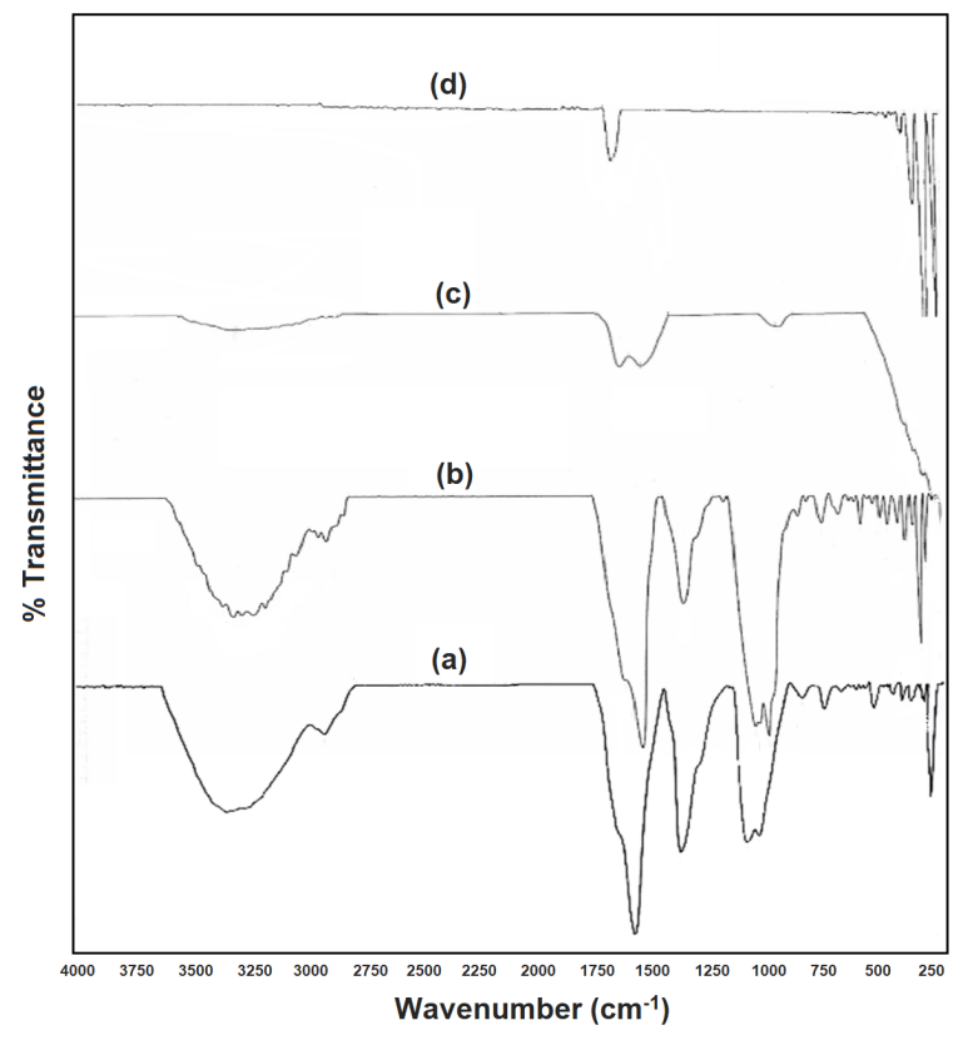

Figure 7. FTIR Spectra of pure fruits extract (a) pure seed extract (b), silver nanoparticle from fruit extract $(\mathrm{c})$, silver nanoparticle from seed extract $(\mathrm{d})$. 
Therefore, in both seed and fruit extract silver Ag-NPs were found around the range of 290 to $490 \mathrm{~cm}^{-}$ ${ }^{1}$. In pure extract fruits and seed there are several band around 2900 to $3500 \mathrm{~cm}^{-1}$ which indicates the Carboxylic acid O-H Stretch, alcohol/phenol O-H Stretch. However, there is also band found around the range of 300 to $1650 \mathrm{~cm}^{-1}$ which indicates the Amide $\mathrm{C}=\mathrm{O}$ Stretch, aromatic $\mathrm{C}-\mathrm{H}$ Bending, aromatic $\mathrm{C}=\mathrm{C}$ bending. It is proven that the phenolic compounds are presence in the extract which work as capping and reducing agent to synthesis Ag-NPs from silver nitrates.

\subsection{Antimicrobial Activity}

Antibacterial test was performed against the Gram-negative bacterium E. coli strain and $P$. aeruginosa by a disk diffusion method. Research shows that biosynthesized Ag-NPs exhibit more antimicrobial activity on gram-negative microorganism than gram-positive ones [26,28]. Figure 7 shows the antimicrobial effect of $E$. coli bacteria in pure silver nitrate (A), fruit extract silver nanoparticle (B), seed extract silver nanoparticle (C). Figure 8 shows the antimicrobial effect of $P$. aeruginosa in fruit extract Ag-NPs (A), seed extract Ag-NPs (B). Both fruit and seed extracts show the similar effect of antimicrobial activity on both bacteria [28].

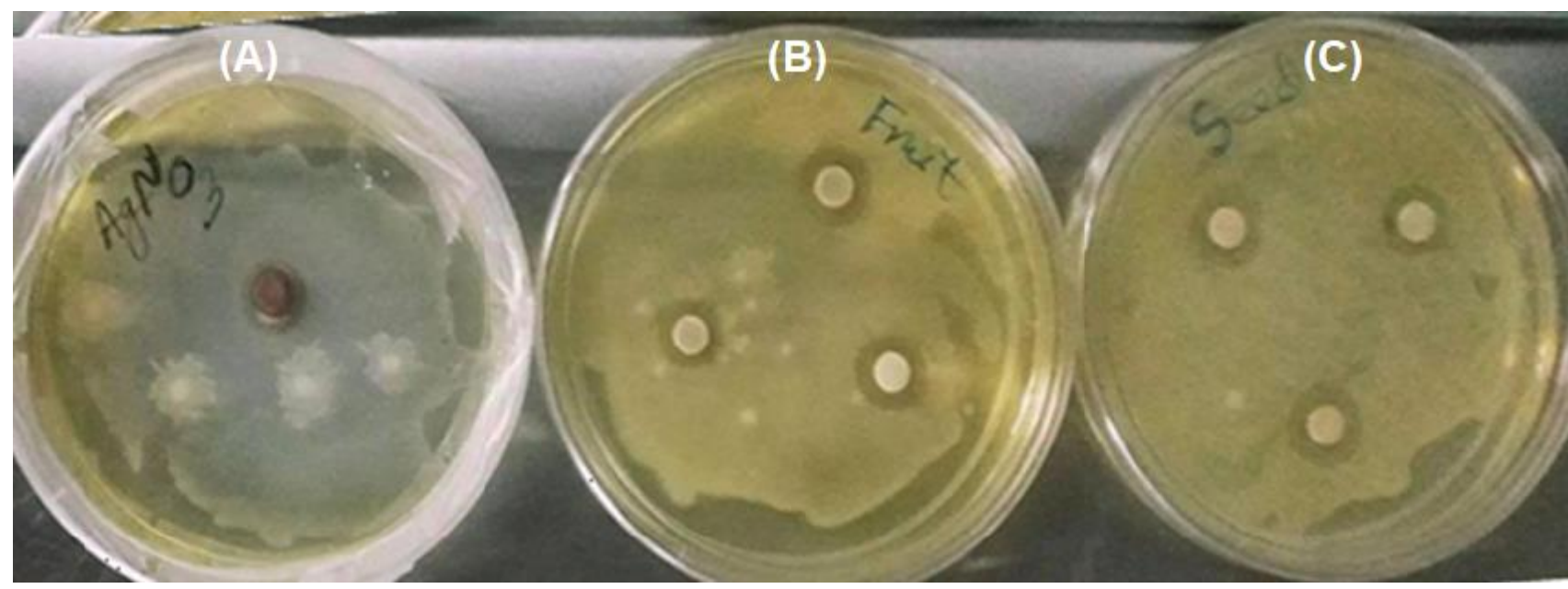

Figure 8. Antimicrobial test of $E$. coli bacteria for $\mathrm{AgNO}_{3}(\mathrm{~A}), \mathrm{Ag}-\mathrm{NPs}$ synthesis in fruit extract (B), Ag-NPs synthesis in seed extract (C).
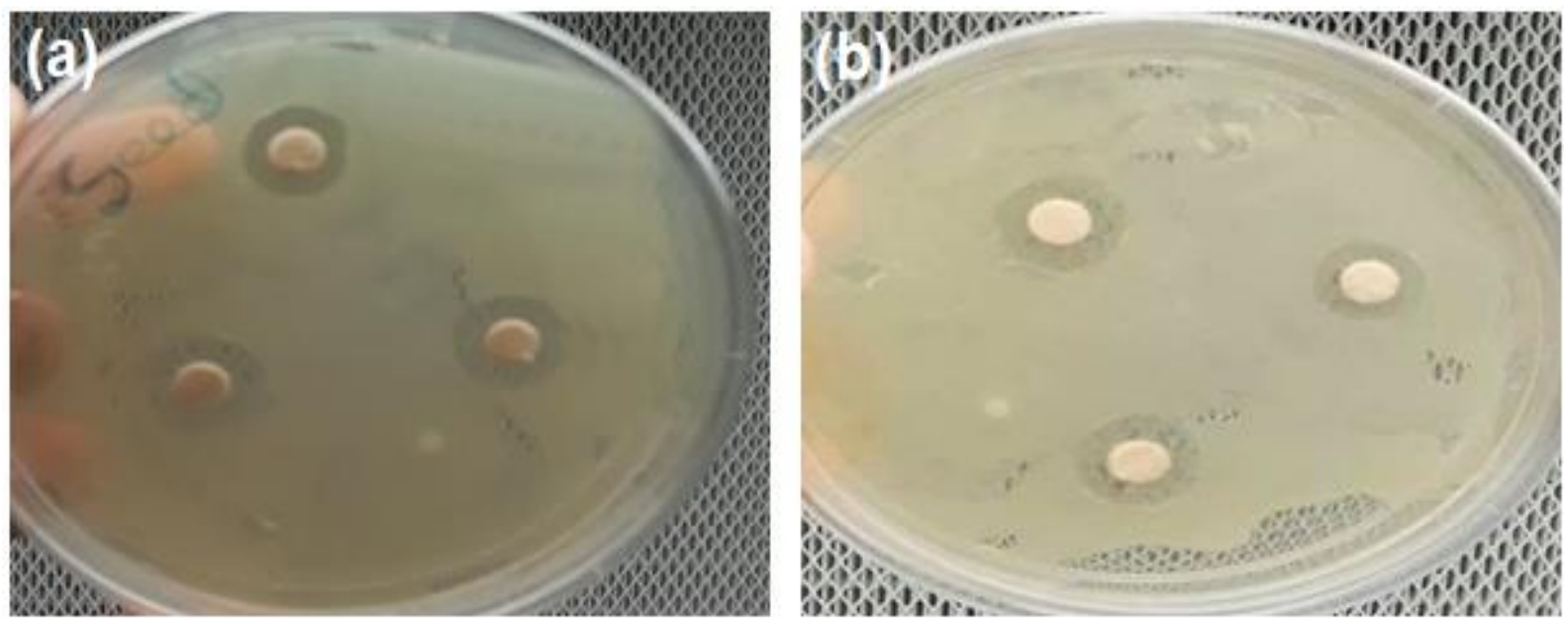

Figure 8. Antimicrobial test of P. aeruginosa fruit extract of Ag-NPs (a), Seed extract of Ag-NPs (b). 


\section{Conclusions}

The green synthesis process of producing nanoparticles has potentially beneficial to produce different structure of nanomaterial. The experiment was done to synthesize Ag-NPs by using Momordica charantia extract which acts as a capping agent. By this method of producing Ag-NPs by the phenolic compounds existing in $M$. charantia extract, the problems of chemical synthesis can be solving which help to reduce the chemical treatment of antimicrobial action in various application. Ag-NPs were successfully characterized by UV-Vis, DLS, FTIR, FESEM, HRTEM and the average size of Ag-NPs is 10-30 nm. These nanoparticles showed antibacterial activity against E. coli bacteria and P. aeruginosa. Due to their small sizes, the nanostructures exhibit unique physicochemical and biological properties (e.g., an enhanced reactive area as well as an ability to cross cell and tissue barriers) that make them a favourable material for biomedical applications as well as other applications.

\section{Acknowledgment}

The authors would like to express sincere gratitude to the Universiti Putra Malaysia for the characterizations supports in Institute of Bioscience and Institute of Advance Technology.

\section{References}

1. B. Ankamwar, M. Chaudhary and M. Sastry. Gold nanotriangles biologically synthesized using tamarind leaf extract and potential application in vapor sensing. Synth. React. Inorg. M., 2005, 35(1), pp. 19-26. doi: 10.1081/SIM-200047527.

2. H. Jahangirian, M. H. S. Ismail, M. J. Haron, R. Rafiee-Moghaddam, K. Shameli and S. Hosseini. Synthesis and characterization of zeolite/ $\mathrm{Fe}_{3} \mathrm{O}_{4}$ nanocomposite by green quick precipitation method. Dig. J. Nanomater. Biostruct., 2013, 8.(4), pp. 1405-1413.

3. M. Irfan, M. Saeed, B. Iqbal, M. Ghazanfar. Application of Plant-Based Natural Product to Synthesize Nanomaterial. Nanomaterials in Biofuels Research, Clean Energy Production Technologies, 2020, Springer. pp. 29-52. doi: 10.1007/978-981-13-9333-4_12.

4. R. Khandanlou, M. Ahmad, H. R. Fard Masoumi, K. Shameli and M. Basri, Rapid adsorption of copper (II) and lead (II) by rice straw $/ \mathrm{Fe}_{3} \mathrm{O}_{4}$ nanocomposite: optimization, equilibrium isotherms, and adsorption kinetics study. PloS one., 2015, 10.(3), pp. 1-19. doi: 10.1371/journal.pone.0120264.

5. A. Amini, M. Latifi, and J. Chaouki. Electrification of materials processing via microwave irradiation: A review of mechanism and applications. Appl. Therm. Eng., 2021, pp. 117003. doi: 10.1016/j.applthermaleng.2021.117003.

6. Z. Izadiyan, K. Shameli, M. Miyake, H. Hara, S. H. Mohd Taib and E. Rasouli, Cytotoxicity assay of plant-mediated synthesized iron oxide nanoparticles using Juglans regia green husk extract. Arab. J. Chem., 2020, 13.(1), pp. 2011-2023. doi: 10.1016/j.arabjc.2018.02.019.

7. P. Singh, Y. J. Kim, D. Zhang, D. C. Yang. Biological synthesis of nanoparticles from plants and microorganisms. Trends Biochem. Sci., 2016. 34(7): pp. 588-599. doi: 10.1016/j.tibtech.2016.02.006.

8. R. Khandanlou, M. Ahmad, K. Shameli and K. Kalantari, Synthesis and characterization of rice straw/Fe3 $\mathrm{O}_{4}$ nanocomposites by a quick precipitation method. Molecules, 2013, 18.(6), 6597-6607. doi: 10.3390/molecules18066597.

9. A. K. Ojha, J. Rout, S. Behera, and P. L. Nayak. Green synthesis and characterization of zero valent Ag-NPs from the leaf extract of Datura metel. Int. J. Chem. Pharm. Res., 2013. 2(1), pp. 31-35. 
10. K. X. Lee, K. Shameli, Y. P. Yew, S. Y. Teow, H. Jahangirian, R. Rafiee-Moghaddam and T. J. Webster. Recent developments in the facile bio-synthesis of gold nanoparticles (AuNPs) and their biomedical applications. Int. J. Nanomed., 2020, 15, pp. 275-300. doi: 10.2147/IJN.S233789.

11. S. Ahmed, M. Ahmad, B. L. Swami, S. Ikram. A review on plants extract mediated synthesis of Ag-NPs for antimicrobial applications: a green expertise. J. Adv. Res., 2016, 7(1), pp. 17-28. doi. 10.1016/j.jare.2015.02.007.

12. P. Shabanzadeh, N. Senu, K. Shameli, F. Ismail, A. Zamanian, and M. Mohagheghtabar. Prediction of silver nanoparticles' diameter in montmorillonite/chitosan bionanocomposites by using artificial neural networks. Res. Chem. Intermed., 2015, 41(5), pp. 3275-3287. doi: 10.1007/s11164-013-1431-6.

13. B. Ajitha, Y. A. K. Reddy, and P. S. Reddy. Biosynthesis of Ag-NPs using Momordica charantia leaf broth: evaluation of their innate antimicrobial and catalytic activities. J. Photochem. Photobiol. B., 2015, 146, pp. 1-9. doi: 10.1016/j.jphotobiol.2015.02.017.

14. P. Shabanzadeh, R. Yusof, and K. Shameli. Modeling of biosynthesized silver nanoparticles in Vitex negundo L. extract by artificial neural network. RSC Advances., 2015, 5(106), pp. 87277-87285. doi: 10.1039/C5RA11940E.

15. J. Grover, and S. Yadav. Pharmacological actions and potential uses of Momordica charantia: a review. J. Ethnopharmacol., 2004, 93(1), pp. 123-132. doi: 10.1016/j.jep.2004.03.035.

16. P. Shabanzadeh, N. Senu, K. Shameli and M. Mohaghegh Tabar. Artificial intelligence in numerical modeling of silver nanoparticles prepared in montmorillonite interlayer space. J. Chem., 2013, 2013, pp. 1-8. doi: 10.1155/2013/305713.

17. S. K. Balavandy, K. Shameli, and Z. Z. Abidin, Rapid and green synthesis of silver nanoparticles via sodium alginate media. Int. J. Electrochem. Sci., 2015., 2015, 10.(1), 486-497.

18. P. Budrat, and A. Shotipruk. Enhanced recovery of phenolic compounds from bitter melon (Momordica charantia) by subcritical water extraction. Sep. Purif. Technol., 2009, 66(1), pp. 125-129. doi: 10.1016/j.seppur.2008.11.014.

19. C. Marambio-Jones, and E.M. Hoek, A review of the antibacterial effects of silver nanomaterials and potential implications for human health and the environment. J. Nanoparticle Res., 2010, 12(5), pp. 1531-1551. doi: 10.1007/s11051-010-9900-y.

20. K. Shameli, M. Ahmad, S. D. Jazayeri, P. Shabanzadeh, H. Jahangirian, M. Mahdavi, and Y. Abdollahi. Synthesis and characterization of polyethylene glycol mediated silver nanoparticles by the green method. Int. J. Mol. Sci., 2012, 13(6 ), pp. 6639-6650. doi: 10.3390/ijms13066639.

21. A. R. Shahverdi, A. Fakhimi, H. R. Shahverdi, S. Minaian. Synthesis and effect of Ag-NPs on the antibacterial activity of different antibiotics against Staphylococcus aureus and Escherichia coli. Nanomedicine: NBM., 2007, 3(2), pp. 168-171. doi: 10.1016/j.nano.2007.02.001.

22. M. Rafique, I. Sadaf, M. S. Rafique, M. B. Tahir. A review on green synthesis of Ag-NPs and their applications. Artif. Cell Nanomed. B., 2017, 45(7), pp. 1272-1291. doi: 10.1080/21691401.2016.1241792.

23. S. Basavaraja, S. D. Balaji, A. Lagashetty. Extracellular biosynthesis of Ag-NPs using the fungus Fusarium semitectum. Mater. Res. Bull., 2008, 43(5), pp. 1164-1170. doi: 10.1016/j.materresbull.2007.06.020.

24. S. Shrivastava, T. Bera, S. K. Singh, G. Singh, P. Ramachandrarao, and D. Dash. Characterization of antiplatelet properties of silver nanoparticles. ACS nano., 2009. 3(6), pp. 1357-1364. doi: 10.1021/nn900277t.

25. V. K. Sharma, R. A. Yngard, and Y. Lin. Silver nanoparticles: green synthesis and their antimicrobial activities. Advances in colloid and interface science, 2009, 145(1-2), pp. 83-96. doi: 10.1016/j.cis.2008.09.002. 
26. K. Shameli, M. Ahmad, S. D. Jazayeri, P. Shabanzadeh, P. Sangpour, H. Jahangirian, Y. Gharayebi. Investigation of antibacterial properties silver nanoparticles prepared via green method. Chem. Cent. J., 2012, 6(1), pp. 73(1-10). doi: 10.1186/1752-153X-6-73.

27. M. Ahmad, J. J. Lim, K. Shameli, N. A. Ibrahim, M. Y. Tay, B. W. Chieng. Antibacterial activity of silver bionanocomposites synthesized by chemical reduction route. Chem. Cent. J., 2012, 6(1), pp. 101(1-9). doi: 10.1186/1752-153X-6-101.

28. G. Singhal, R. Ghavesh, K. Kasariya. Biosynthesis of Ag-NPs using Ocimum sanctum (Tulsi) leaf extract and screening its antimicrobial activity. J. Nanoparticle Res., 2011, 13(7), pp. 2981-2988. doi: org/10.1007/s11051-010-0193-y. 